\title{
Análise de Cenários como ferramenta de atividade educacional em Engenharia de Produção
}

Felipe Ferreira de Lara fflara@ifsp.edu.br 0000-0001-9093-8454

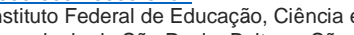
Paunogia de Sao Paulo, Boituva, São Paulo, Brasil.

\section{Roberto Marx}

irobemarx@usp.br

Universidade de São Paulo, São Paulo, São Paulo, Brasil.

\section{Mauro Zilbovicius}

\section{mzilbovi@usp.br}

0000-0001-9154-8503

Universidade de São Paulo, São Paulo, São Paulo, Brasil.

\section{RESUMO}

A presente pesquisa visa analisar as contribuições da análise de cenários como uma ferramenta de atividade educacional para o ensino de engenharia. Para isso, será analisado o plano e a condução de uma disciplina do último semestre do curso de Engenharia de Produção da Escola Politécnica da Universidade de São Paulo. A disciplina pesquisada não possui conteúdo específico pré-definido: o conteúdo dependerá, a cada vez que for ministrado, dos temas em aprofundamento. Na experiência estudada, o tema proposto foi o da Mobilidade Urbana e as atividades de sala de aula foram conduzidas por meio da metodologia da análise de cenários. Desse modo, o artigo propõe-se a analisar a experiência desenvolvida a partir da aplicação desse método, contemplando o plano da disciplina, a forma de condução das aulas e a contribuição para o desenvolvimento de competências e habilidades dos alunos. $\mathrm{O}$ artigo apresenta, ainda, sugestões de melhorias para a disciplina.

PALAVRAS-CHAVE: Cenários. Ensino em engenharia. Engenharia de produção. 


\section{INTRODUÇÃO}

Para Padilha (2001, p.63), realizar o planejamento educacional significa "exercer uma atividade engajada, intencional, científica, de caráter político e ideológico e isenta de neutralidade". De acordo com o autor, planejar é um processo que visa dar respostas a um problema, por meio da definição de meios e fins que direcionem para uma solução e objetivos antes previstos.

Atualmente, em função do nível de competitividade em que a economia atual se encontra, é exigida do ensino em engenharias a necessidade de se moldar à tendência de se buscar a formação de profissionais com capacidade para desempenhar atividades inerentes aos diferentes setores de desenvolvimento (SILVA e CECILIO, 2007).

Para Lacerda Neto et al. (2013), no ensino em engenharia é necessário estimular competências e habilidades que estimulem o processo de inovação, mas com o entendimento da ciência e da tecnologia como fenômenos humanos produzidos em um contexto social, de modo a conscientizar os futuros engenheiros de práticas e valores "não técnicos" que se incorporam em seu exercício profissional. Nesse contexto, o empenho do professor, o planejamento e a condução das disciplinas de um curso de formação em Engenharia compõem um conjunto de elementos decisivos para a eficácia desse processo.

Para Loder (2005) o bom professor problematiza o conteúdo e desafia intelectualmente seus alunos e não se limita a apresentar um conteúdo e mostrar seu conhecimento: o objetivo primordial é o aprendizado do aluno. Assim, uma das estratégias eficazes consiste em trabalhar o conteúdo problematizando situações e solicitando dos alunos soluções. Dessa forma, o professor convida o aluno a participar dos rumos da aula.

Uma forma comum de se problematizar um conteúdo, exigindo distintas soluções é a formulação e análise de cenários. De acordo com Carvalho et al. (2011), o uso de cenários permite uma variedade de potenciais resultados, sem a influência de seus próprios vieses, opiniões e preconceitos, permitindo, desse modo, a reflexão e ensaio de diversos futuros possíveis. Com isso, é possível se adequar aos novos eventos à medida que um dos cenários identificados se concretize, sem a necessidade de uma preparação que envolva altos custos e tempo de preparação.

Portanto, de modo a avaliar as contribuições da análise de cenários como uma ferramenta de atividade educacional para o ensino de engenharia, foi realizado um estudo de caso envolvendo o planejamento e a condução de uma disciplina vinculada ao departamento de Engenharia de Produção da Escola Politécnica da Universidade de São Paulo, ministrada para os alunos de graduação do último semestre do curso, envolvendo essa ferramenta. A disciplina foi ministrada por dois professores e o autor do trabalho teve a oportunidade de atuar como monitor ao longo do semestre.

Para isso, o artigo se divide em um referencial teórico, que subdivide-se nos principais conceitos associados ao ensino de engenharia e à análise de cenários. Em seguida, apresenta-se o método de pesquisa utilizado para, em seguida, apresentar e discutir os resultados obtidos. Ao fim, estabelecem-se as considerações finais sobre a pesquisa. 
Para Cargnin-Stieler e Teixeira (2012), a discussão sobre didática e pedagogia, especialmente as que envolvem as descobertas de pesquisas da ciência cognitiva e aspectos didáticos do processo de ensino e aprendizagem, são extensamente discutidas na preparação dos estudantes nas faculdades de educação, mas não nos cursos de Engenharia.

Para Sousa e Gomes (2011), o atual estágio de desenvolvimento tecnológico transformou a condição de detentor de conhecimento dos profissionais da engenharia, de um conhecimento global para um domínio apenas parcial dos processos produtivos. Uma vez que já não mais detém um saber capaz de elaborar soluções para os problemas complexos da sociedade atual, exige-se um desenvolvimento humanístico para viabilizar a integração dos saberes.

O desafio de ensino dos cursos de engenharia é ter em mente que essa necessidade atual de ensinar, não apenas o que está nos livros, mas também mostrar o que está acontecendo em termos de constantes mudanças tecnológicas e formas de pensar (PAGOTTO e SANTOS, 2013). Desse modo, entende-se que a mudança na formação profissional não se resume em fazer do engenheiro apenas o integrador de soluções, mas torná-lo capaz de compreender as demandas da sociedade e integrar soluções que estejam de acordo com valores sociais. Esses valores seriam desenvolvidos por meio de uma mudança nas disciplinas presentes nos cursos de engenharia (SOUSA e GOMES, 2011).

Santos e Barra (2012) corroboram essa perspectiva ao analisarem que o ensino em engenharias, normalmente, não contempla em suas Diretrizes Curriculares uma proposta de atuação pedagógica por meio da utilização de estratégias interdisciplinares. O que é possível se observar é uma dissociação dos conhecimentos trabalhados em diferentes unidades curriculares (disciplinas) de uma matriz. No entanto, as instituições que se utilizam desses recursos pedagógicos em suas práticas o fazem por necessitarem de ferramentas para o ensino que, se adequadamente aplicadas, dinamizem o currículo e fortaleçam a formação dos educandos.

A esses elementos soma-se ainda que, conforme analisam Silva e Cecílio (2007), no processo de formação de engenheiros ainda ocorrem algumas contradições. Se por um lado engenheiros se tornam professores e ensinam o que sabem fazer; por outro, professores ensinam aquilo que não fazem na prática ou não tiveram vivência.

Desse modo, cria-se uma situação em que uns ensinam em decorrência de exercício de sua profissão, porém, às vezes, sem o reconhecimento da dimensão pedagógica do trabalho docente, uns transmitem a teoria, muitas vezes sem as conexões com a prática. A dissociação teoria e prática dificulta o processo de ensino-aprendizagem, além de acarretar insatisfações a alunos e professores e comprometer os resultados de suas ações (SILVA e CECILIO, 2007).

Portanto, entende-se que é importante o desenvolvimento do professorformador, que tenha domínio profissional e científico em relação ao que se propõem a fazer, que sejam reflexivos e atuem como pesquisadores de sua própria prática. 
Assim, a necessidade de encontrar aporte em ferramentas que privilegiem o ensino enquanto uma ação que se faz dinâmica em todas as suas etapas do processo é o grande desafio dos educadores. Esta ação requer uma profunda reflexão e compreensão de como se dá de fato a relação do aluno com o saber e de como ele constrói as experiências de aprendizagem (SANTOS e BARRA, 2012). Nesse sentido, a análise de cenários contribui para essa reflexão.

\section{ANÁLISE DE CENÁRIOS}

De acordo com Leão et al. (2010), o atual panorama econômico muda constantemente e, cada vez mais, passível a transformações radicais nos ambientes de concorrência de países e empresas. Com isso, as empresas precisam encontrar soluções rapidamente para se adaptarem às novas realidades, e quanto mais se aumentam as incertezas em todas as áreas de conhecimento, também se aumenta a importância da avaliação sobre as perspectivas futuras da realidade.

Desse modo, as técnicas associadas à metodologia de cenários estão se incorporando crescentemente como uma ferramenta real de ação para planejadores e tomadores de decisão nas empresas. Ainda que não seja possível eliminar as incertezas nem definir com exatidão um panorama futuro, as metodologias de construção de cenários contribuem para reduzir as possibilidades de desvios em relação à evolução da realidade. Portanto, a análise de cenários trata-se de elaborar uma prévia de forma estruturada sobre o futuro, a partir da apresentação de sequências de eventos ou de cenas, desdobradas a partir do presente, até um horizonte temporal definido (LEÃO et al., 2010).

Além disso, a construção de cenários permite visualizar tendências e favorece a avaliação de consistência do conjunto de previsões, que compõem as distintas possibilidades sobre o futuro. A partir de tais conjuntos de previsões é possível avaliar pontos fortes e fracos da organização em relação às previsões e a adequação das políticas vigentes em relação às eventuais alternativas. Assim, percebe-se a natureza sistêmica da metodologia, que explora as relações de interdependência entre variáveis e dimensões estratégicas de países e organizações (CARVALHO et al., 2011).

Essa visão sistêmica da metodologia de análise de cenários é corroborada por Buarque (2003), uma vez que, de acordo com o autor, a construção de cenários lida com sistemas altamente complexos, não lineares e dinâmicos, que convivem com contínuas mudanças estruturais e com elevado grau de incerteza sobre os caminhos dessas mudanças. Outro fator ainda analisado pelo autor é que esses cenários devem lidar com realidades nas quais os resultados de uma mudança original não são proporcionais às causas, também múltiplas e diversificadas.

Nessa linha, em termos gerais, Börjeson et al. (2006 apud SOUZA e TAKAHASHI, 2012) classificam os cenários em três tipos:

- cenários preditivos tentam predizer o que vai acontecer no futuro e estão intrinsecamente relacionados aos conceitos de probabilidade e de possibilidade. Geralmente, essas predições fundamentam-se na extrapolação de dados históricos;

- cenários exploratórios tentam explorar situações ou suposições que são consideradas como possíveis em diversas perspectivas. Em geral, os cenários 
exploratórios são elaborados para as análises em longo prazo, a fim de permitir mudanças mais profundas que os cenários de curto prazo;

- cenários normativos, por sua vez, têm como ponto de partida algumas metas explicitamente definidas, de modo que se busca elencar as atividades necessárias para alcançar tais metas no prazo estipulado.

A complexidade dos sistemas quando se aplica a metodologia da análise de cenários depende, principalmente, do objeto que se pretende descrever no futuro. É recomendável o foco em um determinado setor ou ramo produtivo da economia: o macro ambiente de negócios de uma empresa pode ser relativamente menos complexo se estiver limitado a uma dimensão condicionada por fatores políticos e sociais (BUARQUE, 2003).

No entanto, quando se busca elaborar cenários regionais abrangentes, os quais tratem de diversas dimensões determinantes do seu desempenho futuro, passa-se a analisar uma realidade com elevado nível de complexidade. Nesses casos, o resultado costuma conter maior dinamismo e melhor entendimento em relação às tendências a mudanças, a instabilidade e a incerteza (BUARQUE, 2003).

Por fim, é importante reforçar que, como analisam Wright e Spers (2006), elaborar cenários não é um exercício de previsão ou estimativa do futuro, mas sim um esforço embasado de se construir e visualizar descrições plausíveis e consistentes de situações futuras possíveis. Com isso, é possível identificar e apresentar os fatores relevantes entre a situação atual e cada cenário futuro, destacando os aspectos estratégicos relevantes às decisões que precisam ser tomadas.

Portanto, mesmo sendo uma representação parcial e imperfeita do futuro, o cenário, entendido como instrumento de apoio à decisão, precisa abranger as principais dimensões relevantes do problema. Assim, é importante que seus autores se livrem de vícios e pré-julgamentos, ao mesmo tempo em que devem se manter dentro dos limites do conhecimento científico e propor transformações viáveis no horizonte de tempo considerado (WRIGHT e SPERS, 2006).

\section{MÉTODO}

De acordo com Richardson (1985), a abordagem qualitativa busca interpretar e entender a natureza de um fenômeno social, analisar a interação de variáveis, compreender e classificar processos dinâmicos vividos por diferentes grupos sociais.

Para o presente artigo, entende-se que o problema central de pesquisa, ou seja, a avaliação das contribuições da análise de cenários como uma ferramenta de atividade educacional para o ensino de engenharia busca interpretar a natureza de um fenômeno social a partir da interação especialmente da análise de cenários dentro do contexto educacional. Por isso, entende-se que a abordagem qualitativa pode descrever a complexidade de forma mais adequada para o problema de pesquisa.

Tanto para Martins (2004) quanto para Gunther (2006), uma vez que a abordagem qualitativa trabalha com unidades sociais, ela privilegia os estudos de caso. Yin (2001, p. 32) define estudo de caso como um método de pesquisa que "investiga um fenômeno contemporâneo dentro do seu contexto da vida real, 
especialmente quando os limites entre o fenômeno e o contexto não estão claramente definidos". Assim, optou-se como procedimento utilizado para a pesquisa o estudo de caso, ao analisar a experiência obtida na disciplina vinculada à Escola Politécnica da Universidade de São Paulo.

Além disso, para Yin (2001), o estudo de caso contempla especialmente duas fontes de evidências: observação direta e série sistêmica de entrevistas. Desse modo, para a coleta de dados foram utilizadas as técnicas de observação direta (o autor do trabalho atuou como monitor da disciplina) e entrevistas narrativas com os professores responsáveis pela disciplina.

\section{RESULTADOS}

A apresentação, análise e discussão dos resultados estão divididas em quatro subtópicos. O primeiro deles busca contemplar um panorama geral de apresentação da disciplina, sua estrutura e sua forma de organização. O segundo subtópico apresenta e discute os objetivos da disciplina. O terceiro subtópico explora a condução das atividades ao longo do semestre. Por fim, o quarto subtópico analisa e discute alguns dos principais resultados obtidos em relação à proposta do presente artigo.

\section{ESTRUTURA E ORGANIZAÇÃO DA DISCIPLINA}

A disciplina possui 2 créditos aula, contemplando uma carga horária total de 30 horas, ao longo de um semestre. É ministrada para os alunos de $5^{\circ}$ ano $\left(10^{\circ}\right.$ semestre) do curso de Engenharia de Produção da Escola Politécnica da Universidade de São Paulo. Foi conduzida por dois professores do departamento de Engenharia de Produção, com uma divisão de turma para cada docente e o autor do artigo como monitor e colaborador da disciplina, se dividindo entre ambas as classes.

De acordo com os professores responsáveis, não se trata de uma disciplina tradicional com conteúdo específico pré-definido. Este conteúdo dependerá, a cada vez que for ministrada, dos temas em aprofundamento. No entanto, em termos gerais, a metodologia de abordagem pode ser assim descrita:

1. Exercícios de formulação dos problemas a serem tratados.

- Produzir as questões relevantes (por quê? como?)

- Identificar os grupos de interesse e sua capacidade de intervenção no problema

- Identificar a história do problema (sob que condições se decide, hoje, o problema?)

2. Exercícios de aprofundamento da compreensão do problema

- Pesquisar respostas na literatura e/ou outras fontes (pessoas, por exemplo)

- Identificar similaridades e diferenças com outros cenários (por exemplo, em problemas urbanos, comparar outras cidades).

3. Exercício de desenvolvimento de soluções que devem ser viáveis, sujeitas a restrições. 
4. Debates do material produzido entre os alunos e com convidados especialistas no assunto.

5. Oficinas de finalização de um dossiê a respeito do problema (relatório final).

Em relação à avaliação não foi aplicada uma prova discursiva sobre o tema abordado. A composição da nota foi estabelecida por meio de entregas parciais de relatórios, avaliados pelo monitor da disciplina e apresentação final de disciplina contendo as propostas e cenários estabelecidos pelos alunos. Na apresentação final, além dos professores responsáveis e o monitor da disciplina, foram convidados especialistas sobre o tema para acompanharem as propostas apresentadas pelos alunos.

\section{OBJETIVOS DA DISCIPLINA}

De acordo com os professores responsáveis, o objetivo central é contribuir para desenvolver um conjunto de competências e habilidades nos alunos que permita a compreensão e a sistematização de distintas possibilidades de ser abordar problemas amplos e complexos. Também se entende que um engenheiro deva contribuir com soluções para a sociedade, portanto, os temas propostos devem, necessariamente, abordar temas atuais da sociedade e da economia brasileira, identificando suas múltiplas determinações, em geral técnicas, econômicas, políticas, sociais, etc.

Além disso, os professores responsáveis pela disciplina também apontam como fundamental desenvolver competências e habilidades voltadas ao exercício da capacidade de crítica para a formulação de soluções para problemas de grande escala. Para isso, é importante expor estas soluções à análise de especialistas, buscando distanciamento tanto da abordagem ideológica como da abordagem jornalística dos problemas, mas considerando essas abordagens (e outras) como parte do equacionamento dos problemas analisados.

Outro fator importante a ser considerado é a posição da disciplina na grade do curso de Engenharia de Produção. De acordo com os professores, os alunos são praticamente Engenheiros, uma vez que estão no $10^{\circ}$ semestre de curso, no qual são poucas as disciplinas e, de modo geral, há uma agitação em termos de início profissional e posicionamento no mercado de trabalho. Portanto, uma disciplina de ordem mais prática, que simule situações reais de complexidade e contendo uma dinâmica que aborde a resolução de problemas reais se faz pertinente.

Como uma forma de desenvolver habilidades e competências nos alunos, especialmente no contexto de "quase formandos" em que a maior parte da turma se encontrava, os docentes partiram de uma proposta de problematizar uma situação real complexa e estimular os alunos a desenvolverem soluções de forma sistêmica e profissional.

Os docentes desta disciplina entendem que devem prover fontes e indicações de leitura e de pesquisa para os alunos a respeito do tema e subtema. No entanto, a capacidade de identificar informações é parte do papel esperado a ser desenvolvido pelos alunos.

Além disso, para os docentes da disciplina é importante provocar os alunos, com dúvidas e questionamentos e assumir um papel de tomador de decisão sobre as proposições que são feitas pelos alunos. Por fim, os docentes da disciplina 
também entendem um papel importante como coordenador dos debates, buscando desenvolver questões para os temas. Com isso, a dinâmica da aula, juntamente com o tempo para debates em grupo, foi permeada com discussões e abordagens como: há solução pronta? Quais os limites das soluções técnicas? Já se resolveu isso ou problema semelhante em outro local? Quais foram os resultados? Isso é financeira e legalmente viável?

\section{CONDUÇÃO DAS ATIVIDADES}

A proposta foi dividir a turma em duas, cada uma com 9 grupos de cerca de 5 alunos para cada professor, totalizando 18 grupos. Foram propostos 9 temas a serem sorteados:

1. Como tornar o car sharing uma iniciativa que contribua positiva e significativa/ com o problema da mobilidade urbana de SP e, ao mesmo tempo, tornar-se negócio atrativo do ponto de vista do empreendedor? - comum às duas turmas;

2. Como melhorar significativamente a mobilidade dos moradores de regiões específicas de São Paulo para as outras partes da cidade? - um grupo ficou com a Zona Leste e outro com a Zona Sul;

3. Como rever custos, formas de tarifação, contratação e subsídios de maneira a melhorar significativamente o serviço de ônibus da cidade de São Paulo? comum às duas turmas;

4. Soluções para melhoria significativa da qualidade dos serviços prestados pela CPTM. - um grupo ficou Linha 7 Diamante e outro grupo ficou com Linha 8 Rubi da CPTM de SP;

5. Como melhorar significativamente a mobilidade entre Guarulhos e São Paulo, incluindo os fluxos "de" e "para" o aeroporto de Cumbica? - comum às duas turmas;

6. Como um pedágio urbano na cidade de São Paulo poderia contribuir com a melhoria da mobilidade? - comum às duas turmas;

7. Como reduzir acidentes por meio da segurança viária em São Paulo? comum às duas turmas;

8. Como financiar a ampliação expressiva da rede de metrô em SP, via PPPs e iniciativas complementares? - comum às duas turmas;

9. Como melhorar significativamente a qualidade das calçadas em SP integrando-as com as várias dimensões da mobilidade? - comum às duas turmas.

A partir da definição dos subtemas, os alunos foram instruídos a conduzir as atividades por meio de algumas etapas. A primeira delas seria uma formulação para o problema a ser tratado, ou seja, a partir das perguntas/temas qual seria o problema de pesquisa a ser identificado. Em seguida, partiu-se para o diagnóstico do problema: soluções técnicas possíveis, mapeamento de interesses associados ao problema; levantamento de aspectos legais e institucionais que afetam a questão, fatores de natureza social, cultural, política, etc. 
A perspectiva desenvolvida foi bem alinhada a definição de Leão et al. (2010), ao buscar elaborar de forma estruturada sequências de eventos ou de cenas desdobradas a partir do presente, até um horizonte temporal definido.

Para a melhor identificação dos problemas e possíveis soluções, foi demandado o contato com o que existe como referência para o tratamento do tema: literatura, experiência em outros locais, no Brasil e no exterior e contato com interlocutores experientes ou agentes na questão (dois especialistas em mobilidade urbana foram convidados a ministrar palestras para a turma).

A partir disso, foi possível criar diversos cenários para, ao fim da disciplina, debater com os docentes e colegas por meio de uma apresentação oral e de um relatório final. A expectativa foi a de se criar os cenários exploratórios, conforme identifica Börjeson et al. (2006).

\section{RESULTADOS OBTIDOS}

De acordo com os professores responsáveis pela disciplina o resultado foi considerado ótimo, especialmente no que se refere não só à criatividade das propostas apresentadas, mas principalmente em relação à condução e estruturação das resoluções.

No entanto, é importante que algumas considerações sejam feitas. A disciplina analisada não possui um documento estruturado para a apresentação do plano de disciplina. Do mesmo modo como o plano de fundo da Mobilidade Urbana analisado para o caso apresentado, a disciplina poderia apresentar outras questões como a Saúde, Habitação, Educação, dentre outros. Este conteúdo dependerá, a cada vez que for ministrada, dos temas em aprofundamento.

No entanto, mesmo em função da variação de temas que a disciplina carrega, apresenta uma estrutura que se espera para um plano de disciplina, assim como informações adicionais pertinentes ao desenvolvimento do tema. Vale ressaltar que as aulas planejadas estavam disponíveis aos alunos desde o início da disciplina e foram cumpridas até o final do curso.

Um dos pontos fortes do plano de aula foram os objetivos que devem ser apresentados no plano de disciplina. Ao longo da condução da disciplina, os objetivos tornam-se evidentes no decorrer do curso, em decorrências dos tópicos abordados e das habilidades e competências que os alunos desenvolvem assistindo se aprofundando nos temas, buscando a opinião de especialistas e estruturando uma solução de forma sistêmica.

Por outro lado, embora seja possível perceber a motivação dos alunos na condução das atividades propostas, foi possível observar a falta de um questionário tanto no início quanto ao fim, abordando inicialmente expectativas e conhecimentos anteriores quanto um relato sobre melhorias possíveis para o esquema proposto da disciplina.

A constatação da boa concepção da disciplina se dá por meio da análise da qualidade das soluções propostas pelos alunos. Bastante próxima a uma simulação de um projeto da vida real, os alunos apresentaram propostas interessantes e criativas. Na rodada final de apresentações, um especialista da ANTP (Associação Nacional de Transportes Públicos em Mobilidade Urbana) acompanhou as 
apresentações e se mostrou bastante surpreso com a qualidade das apresentações e das propostas geradas.

Por fim, ainda vale uma proposta de melhoria no sentido de confrontação de resultados. Como a disciplina foi dividida em duas turmas, cada uma com os mesmos temas, um confronto de resultados também poderia contribuir para incrementar o desenvolvimento de outras competências e habilidades, como capacidade de argumentação, de raciocínio e de dedução, dentre outras, além do próprio aprendizado técnico para cada integrante dos grupos.

\section{CONSIDERAÇÕES FINAIS}

O uso de cenários permite explorar uma variedade de potenciais resultados, permitindo, a reflexão sobre diversos futuros possíveis. Ao envolver a necessidade de entendimento e estruturação de um problema complexo, a aplicação dessa metodologia colabora para o desenvolvimento de atividades educacionais voltadas ao ensino de engenharia. $O$ caso analisado na presente pesquisa se mostrou bastante positivo em termos de qualidade de material final gerado e em termos de motivação para os alunos.

Partindo-se especialmente da perspectiva da qual esse grupo de alunos eram "quase formandos", essa metodologia se mostrou bastante importante para estimular o desenvolvimento de habilidades e competências ao problematizar uma situação real complexa e exigindo-se soluções de forma sistêmica e profissional.

Também é importante se destacar o fato de "provocar" os alunos com temas adequados: é importante para um engenheiro contribuir com soluções para a sociedade, portanto, os temas propostos devem, necessariamente, abordar temas atuais da sociedade e da economia brasileira, identificando suas múltiplas determinações.

Como futuras pesquisas é interessante confrontar os resultados obtidos entre grupos de alunos com formações distintas, de modo a agregar e gerar discussões sobre as soluções encontradas. Além disso, evidentemente, poderão ser abordados outros temas carentes no país como a Saúde e a Educação. A pesquisa não pretende ser conclusiva, mas abre-se uma oportunidade entusiasta da metodologia aplicada, especialmente dentro de um contexto prático e de contribuição social. 


\title{
Scenario analysis as an educational activity in production engineering
}

\begin{abstract}
This research aims to analyze the contributions of scenario analysis as a tool for educational activity for engineering education. For this, the plan of a discipline of the last semester of Production Engineering at the Polytechnic School of the University of São Paulo will be analyzed. The discipline has not investigated specific predefined contente and depends each time the subjects in depth. In this paper, the subject is the Urban Mobility and the activities of the classroom were conducted using the methodology of scenario analysis. Therefore, this article proposes to analyze the experience gained from the application of this method, considering the plan of discipline, how to conduct classes and contribution to the development of skills and abilities of students. The article also presents suggestions for improvements to the discipline and the use of scenario analysis methodology.
\end{abstract}

KEYWORDS: Scenarios. Teaching engineering. Industrial engineering. 


\section{REFERÊNCIAS}

BUARQUE, S. C. Metodologia e técnicas de construção de cenários globais e regionais (Texto para discussão, n. 939). Brasília: IPEA, 2003.

CARGNIN-STIELER, M.; TEIXEIRA, M. C. M. Ensino de engenharia e formação pedagógica: uma aproximação necessária. In: Anais do XL COBENGE - Congresso Brasileiro de Ensino de Engenharia, Belém, PA, 2012.

CARVALHO, D. E.; SUTTER, M. B.; POLO, E. F.; WRIGHT, J. T. C. Construção de cenários: apreciação de métodos mais utilizados na administração estratégica. In: Anais do XXXV EnANPAD - Encontro da Associação Nacional de Pós-Graduação e Pesquisa em Administração, Rio de Janeiro, RJ, 2011.

GUNTHER, H. Pesquisa qualitativa versus pesquisa quantitativa: esta é a questão? Psicologia: teoria e pesquisa, v. 22, n. 2, p. 201-210, 2006.

LACERDA NETO, J.; PEREIRA, V.; POLASTRINI, R.; POLASTRINI, G. Uma proposta de atividade sócio técnica para o ensino de engenharia. In: Anais do XLI COBENGE Congresso Brasileiro de Ensino de Engenharia, Gramado, RS, 2013.

LEÃO, P. R. C.; ROCHA NETO, I.; FERNANDES, J. L.; XAVIER, A. K. A relevância da metodologia de cenários para instituições financeiras em momentos de crise. Future Studies Research Journal, São Paulo, v. 2, n. 2, pp. 38 - 55, Jul./dez. 2010.

LODER, L. L. O bom professor de engenharia: visão dos alunos versus visão dos professores - aproximações e distanciamentos. In: Anais do XXXIII COBENGE Congresso Brasileiro de Ensino de Engenharia, Campina Grande, PB, 2005.

MARTINS, H. Metodologia qualitativa de pesquisa. Educação e Pesquisa, v. 30, n. 2, p. 289-300, 2004.

PADILHA, P. R. Planejamento Dialógico: Como construir o projeto políticopedagógico da escola. São Paulo: Ed. Cortez, 2001.

PAGOTTO, C. R.; SANTOS, M. E. O uso de mídias digitais no ensino de Engenharia Mecânica na Universidade Federal de Juiz de Fora. In: Anais do XLI COBENGE Congresso Brasileiro de Ensino de Engenharia, Gramado, RS, 2013. 
SANTOS, M. C. C.; BARRA, S. R. O projeto integrador como ferramenta de construção de habilidades e competências no ensino de engenharia e tecnologia. In: Anais do XL COBENGE - Congresso Brasileiro de Ensino de Engenharia, Belém, PA, 2012.

SILVA, L. P.; CECILIO, S. A mudança no modelo de ensino e de formação na engenharia. Educação em Revista, Belo Horizonte, v. 45. p. 61-80. jun. 2007.

SOUSA, C. M. e GOMES, G. F. A importância do enfoque CTS na graduação de engenheiros. Educação e Tecnologia, v. 15, n. 2, 2011.

SOUZA, I. D.; TAKAHASHI, V. P. A visão de futuro por meio de cenários prospectivos: uma ferramenta para a antecipação da inovação disruptiva. Future Studies Research Journal, São Paulo, v.4, n.2, pp. 102-132, Jul./Dez. 2012.

YIN, R. Estudo de caso: planejamento e métodos. Porto Alegre: Bookman, 2001.

WRIGHT, J. T. C.; SPERS, R. G. O país no futuro: aspectos metodológicos e cenários. Estudos Avançados, São Paulo, v. 20, n. 56, pp. 13-28, 2006.

Recebido: 07 de dez. de 2014

Aprovado: 07 de jun. de 2016

DOI: $10.3895 /$ rbect.v9n1.1952

Como citar:

LARA, F. F. DE; MARX, R.; ZILBOVICIUS, M. Análise de Cenários como ferramenta de atividade

educacional em Engenharia de Produção. Revista Brasileira de Ensino de Ciência e Tecnologia, v. 9, n.

1, p. 247-259, jan./abr. 2016. Disponível em: <https://periodicos.utfpr.edu.br/rbect/article/view/1952>.

Acesso em: xxx

Correspondência:

Felipe Ferreira de Lara:

Zélia de Lima Rosa, 100, Portal dos Pássaros, Boituva, SP, 18550-000

Roberto Marx:

Av. Prof. Almeida Prado, 128, Cidade Universitária, São Paulo, SP, 05508-070

Mauro Zilbovicius:

Av. Prof. Almeida Prado, 128, Cidade Universitária, São Paulo, SP, 05508-070

Direito autoral: Este artigo está licenciado sob os termos da Licença Creative Commons-Atribuição 4.0 Internacional. 